\title{
A Rare Bone Dysplasia and Chronic Lung Disease
}

\author{
K.P. Dawson a L.I. Al-Gazalia $\quad$ D. Bakalinova ${ }^{b}$ \\ Departments of a Paediatrics and ${ }^{\mathrm{b}}$ Radiology, Faculty of Medicine and Health Sciences, \\ United Arab Emirates University, Al-Ain, United Arab Emirates
}

\section{Key Words}

Spondylo-meta-epiphyseal dysplasia . Chronic lung disease

\section{Abstract}

Objective: To illustrate the development of chronic lung disease in an 11-year-old child with spondylo-meta-epiphyseal dysplasiaabnormal calcification type. Method: Historical review and radiological investigation by high resolution computerized tomography of the thorax. Results: Severe bronchiectasis with a mosaic perfusion pattern was demonstrated. The onset of lung disease was insidious in the absence of a history of recurrent respiratory infection and symptoms. Conclusion: We postulate that the rigidity of the chest wall led to restrictive lung disease. Children with this type of dysplasia need careful monitoring of their respiratory status during their early years.
\end{abstract}

\begin{tabular}{ll}
\hline KARGER & (1) 1999 S. Karger AG, Basel \\
1011-7571/99/0083-0237\$17.50/0 \\
$\begin{array}{l}\text { Fax +4161306 1234 } \\
\text { E-Mail karger@karger.ch } \\
\text { www.karger.com }\end{array}$ & $\begin{array}{l}\text { Accessible online at: } \\
\text { http://BioMedNet.com/karger }\end{array}$
\end{tabular}

\section{Introduction}

A small number of patients with spondylometa-epiphyseal dysplasia-abnormal calcification type (SMEDC), a rare bone dysplasia, have been described [1-3]. Abnormal calcification, a narrow thorax with short flared ribs are seen characteristically in these patients and in addition, they have short stature and short limbs. Five of the last 10 patients described with the condition have had a history of recurrent respiratory infection and have been described as having obstructive or restrictive lung disease which resulted in the death of 2 children. One child previously described by us [3] has now such a history and has been assessed and evaluated radiologically at the age of 11 years and was found to have evidence of chronic lung disease.

Prof. K.P. Dawson

Department of Paediatrics, Faculty of Medicine and Health Sciences UAE University, PO Box 17666

Al-Ain (United Arab Emirates)

Tel. +971 35039 429/672000, Fax +9713672022 


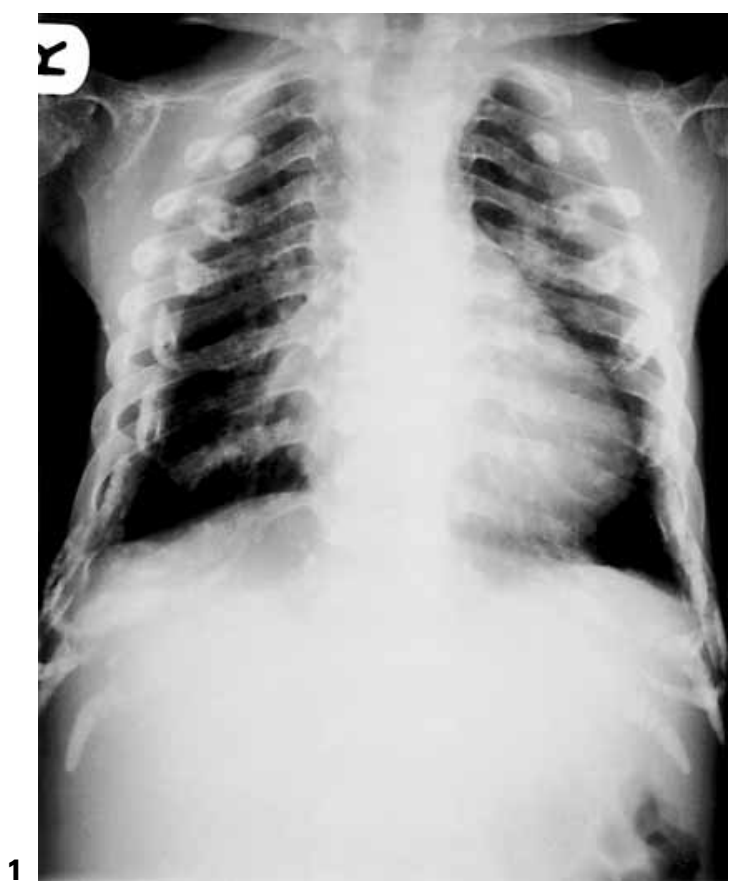

Fig. 1. Anteroposterior film of chest showing broad flat ribs and costochondral calcification.

Fig. 2. Axial slice at the main bronchus level showing a mosaic perfusion pattern to be present.

Fig. 3. Cylindrical bronchiectasis with thickened walls in the right middle lobe and lingula.

\section{The Patient}

N.Y. is an 11-year-old girl, the first of 2 children, whose parents are of Egyptian nationality and are first cousins. She and her brother were diagnosed as having SMEDC at the ages of 8 and 6 years, respectively. N.Y. has been subject to frequent respiratory infections in the past, but none severe enough to warrant hospital admission or investigation. She was further evaluated in the light of the history of respiratory illness and her known thoracic skeletal anomalies.

Her height and weight were below the third percentile. There was no finger clubbing, although her fingers are broad and short. Her respirations were of a panting nature. Her short neck was held in extension. Her chest has an increased anteroposterior diameter and a pidgeon deformity. Despite normal intelligence and a good understanding of the requirements, she was un-
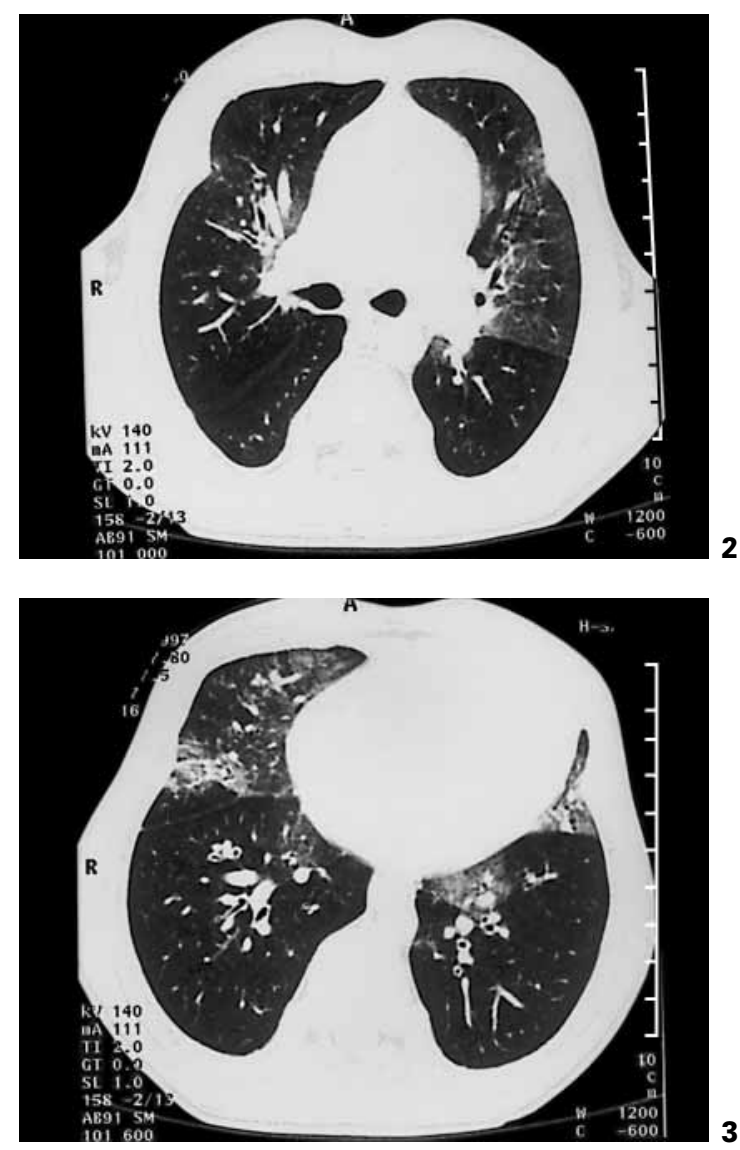

able to perform spirometry and to do peak expiratory flow testing. Tests of her immune function were normal, and included lymphocyte subset testing. A chest radiograph showed a narrow thorax with broad ribs and costochondral calcification (fig. 1). High resolution scanning of her chest revealed evidence of fibrosis which was shown as a mosaic perfusion pattern involving segments of the upper, middle and lower lobes (fig. 2). There was also evidence of cylindrical bronchiectasis with thickened walls in the right middle lobe and lingula and in the posterior segments of the lower lobes (fig. 3). The tracheal diameter was $8 \mathrm{~mm}$ at the level of the aortic arch (fig. 4). The chondrodysplasia is manifest by a punctated non-developed sternal end of the ribs. The posterior parts were the best developed. Most of the elements of the sternal bone are missing due to chondrodysplastic change (fig. 5). Movements of the thorax appeared to be compromised during res- 


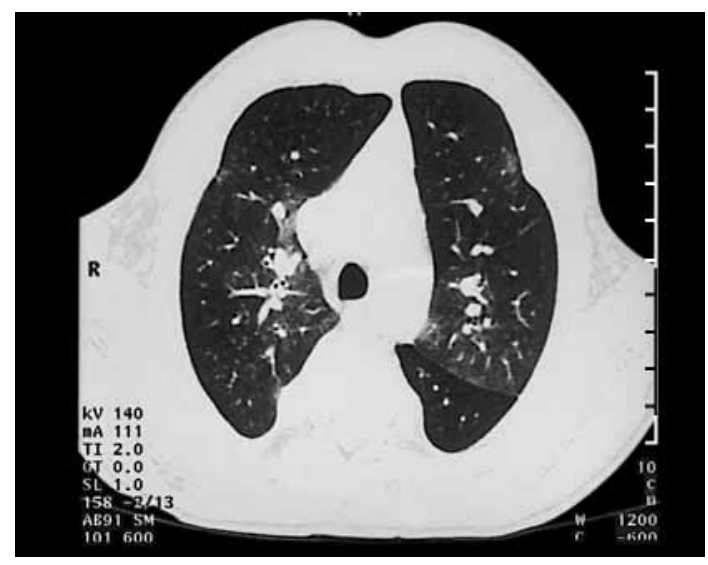

Fig. 4. Mosaic perfusion pattern.

piration. A ventilation perfusion scan showed patchy ventilation in the anterior segments of both lungs, particularly mid zones. The perfusion image showed a corresponding pattern and there was no mismatching. The right middle lobe and the lingula were the poorest ventilated and perfused parts of the lungs.

\section{Discussion}

Disorders which result in poor development of the thorax are usually associated with abnormalities in the osseous and cartilaginous growth. Known conditions which give rise to this situation are achondroplasia, Jeune syndrome and spondylo-epiphyseal dysplasia. In such syndromes, the ribs are typically very short and horizontal. The chest has an increased anteroposterior diameter and decreased mobility. The rigidity and small size of the chest causes restrictive lung disease [4].

We present an example of the rare SMEDC. This autosomal recessive type of SMEDC is characterized by specific radiological abnormalities associated with abnormal calcification involving the epiphyses, ligaments and chondral tissue. Of the 10 cases

A Rare Bone Dysplasia and Chronic Lung Disease

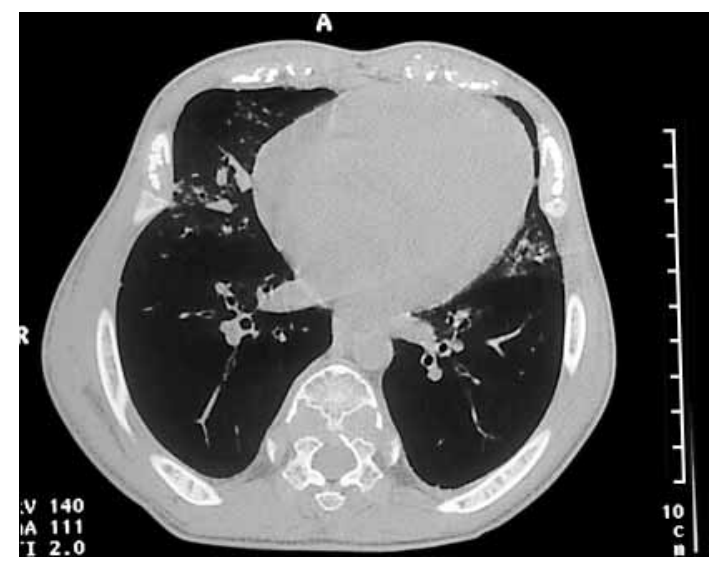

Fig. 5. Chondrodysplasia manifested by changes in ribs, sternum and vertebral bodies.

previously reported, 2 had experienced respiratory infections and 3 developed obstructive/ restrictive lung disease leading to death in 2 of them. These complications are thought to result from a narrow, relatively immobile chest and progressive calcification of the costochondral junctions, tracheal cartilage and cartilaginous structures of the neck. However, none of the patients reported had a detailed study of their immunological status. Furthermore, lung involvement in this syndrome has not been documented radiologically. Our patient is the oldest child reported and the first to have documented, detailed radiological studies of the lungs. It is interesting to note the insidious effect of the disorder upon the lungs. While frequent non-specific respiratory infections with cough and nasal discharge were reported, at no time, however, was the child referred to the hospital or admitted because of marked respiratory symptoms. There has never been marked respiratory distress or failure. However, the child is dyspnoeic at rest with a panting type of respiration and utilizes her abdominal muscles predominantly. She is tachypnoeic at rest also, but is not cyanosed or clubbed.

Med Principles Pract 1999:8:237-240 239 
Despite this, the findings on high resolution CT scanning are extensive, with fibrosis, bronchiectasis and probable bronchiolitis. The right middle lobe and lingula are specifically affected and to a lesser extent the lower lobes. No formal spirometric assessment could be carried out due to the practical difficulty of her being able to maintain a deep breath and perform any form of forced expiratory flow. Numerous attempts were carried out, however, to try and get her to perform these functions.

Not only does the child have an abnormal sternum and ribs, the thoracic bodies and the trachea and bronchus are also abnormal. The large diameter of the main bronchus can be seen in figure 4 . The left measures $1 \mathrm{~cm}$ while the right main bronchus measures $8 \mathrm{~mm}$ at the level of the bifurcation.
In this child, chronic lung disease in the form of fibrosis, bronchiectasis and bronchiolitis has resulted from the abnormalities of the thorax and possibly the tracheobronchial system also. These in turn caused rigidity of the chest wall and subsequent restrictive lung disease. Thus, the child may have been unable to cough properly, which led to the retention of secretions, recurrent episodes of low grade pneumonia and hence bronchiectasis. Despite this, the onset of the lung disease has been insidious. The previous 2 children described in the literature died at an earlier age than our patient. SMEDC needs to be added to the list of causes of thoracic deformity resulting in chronic lung disease. Children with this bone dysplasia need to be carefully monitored and their respiratory status frequently assessed.

\section{References}

1 Borochowitz Z, Langer LO Jr, Gruber HE, Lachman R, Katznelson MB, Rimoin DL: Spondylo-metaepiphyseal dysplasia, short limbhand type: A congenital familial skeletal dysplasia with distinctive features and histopathology. Am J Med Genet 1993;45:320-326.
2 Langer LO, Wolfson BJ, Scott CI, Reid CS, Schidlow DV, Millar EA, Borns PF, Lubicky JP, Carpenter BLM: Further delineation of spondylo-meta-epiphyseal dysplasia, short limb-abnormal calcification type, with emphasis on diagnostic features. Am J Med Genet 1993; 45:488-500.
3 Al-Gazali LI, Bakalinova D, Sztriha L: Spondylo-meta-epiphyseal dysplasia, short limb, abnormal calcification type. Clin Dysmorphol 1996; 5:197-206.

4 Vinocur C, Schidlow DV: Chest wall deformities; in Schidlow DV, Smith DS (eds): A Practical Guide to Pediatric Respiratory Disease. Philadelphia, Hanley \& Belfus, 1994. 